\title{
Model Predictive Control of Offshore Power Stations With Waste Heat Recovery
}

\author{
Pierobon, Leonardo; Chan, Richard; Li, Xiangan; Lyengar, Krishna; Haglind, Fredrik; Ydstie, Erik
}

Published in:

Journal of Engineering for Gas Turbines and Power

Link to article, DOI:

$10.1115 / 1.4032314$

Publication date:

2016

Document Version

Peer reviewed version

Link back to DTU Orbit

Citation $(A P A)$ :

Pierobon, L., Chan, R., Li, X., Lyengar, K., Haglind, F., \& Ydstie, E. (2016). Model Predictive Control of Offshore Power Stations With Waste Heat Recovery. Journal of Engineering for Gas Turbines and Power, 138(7), 071801. https://doi.org/10.1115/1.4032314

\section{General rights}

Copyright and moral rights for the publications made accessible in the public portal are retained by the authors and/or other copyright owners and it is a condition of accessing publications that users recognise and abide by the legal requirements associated with these rights.

- Users may download and print one copy of any publication from the public portal for the purpose of private study or research.

- You may not further distribute the material or use it for any profit-making activity or commercial gain

- You may freely distribute the URL identifying the publication in the public portal 


\title{
Model predictive control of offshore power stations with waste heat recovery
}

\author{
Leonardo Pierobon* \\ Ph.D. \\ Department of Mechanical Engineering \\ Technical University of Denmark \\ Kgs. Lyngby, Denmark 2800 \\ Email: Ipier@mek.dtu.dk
}

Richard Chan

Ph.D.

Industrial Learning Systems Inc.

Pittsburgh, Pennsylvania 15101

Email: khchan@ilsystems.net

\section{Xiangan Li}

M.Sc. Chemical Engineering

Department of Chemical Engineering

Carnegie Mellon University

Pittsburgh, Pennsylvania 15213

Email: lixiangan05572@gmail.com

\section{Fredrik Haglind}

Associate Professor

Department of Mechanical Engineering

Technical University of Denmark

Kgs. Lyngby, Denmark 2800

Email: frh@mek.dtu.dk

\author{
Krishna lyengar \\ M.Sc. Chemical Engineering \\ Department of Chemical Engineering \\ Carnegie Mellon University \\ Pittsburgh, Pennsylvania 15213 \\ Email: krishna@alumni.cmu.edu
}

\author{
Erik Ydstie \\ Professor \\ Department of Chemical Engineering \\ Carnegie Mellon University \\ Pittsburgh, Pennsylvania 15213 \\ Email: ydstie@cmu.edu
}

\begin{abstract}
The implementation of waste heat recovery units on oil and gas offshore platforms demands advances in both design methods and control systems. Model-based control algorithms can play an important role in the operation of offshore power stations. A novel regulator based on a linear model predictive control coupled with a steady-state performance optimizer has been developed in the Simulink language and is documented in the paper. The test case
\end{abstract}

*Address all correspondence related to ASME style format and figures to this author. 
is the regulation of a power system serving an oil and gas platform in the Norwegian Sea. One of the three gas turbines is combined with an organic Rankine cycle turbogenerator to increase the energy conversion efficiency. Results show a potential reduction of frequency drop up to $40 \%$ for a step in the load set-point of 4 MW, compared to proportional-integral control systems. Fuel savings in the range of 2 - $3 \%$ are also expected by optimizing on-the-fly the thermal efficiency of the plant.

\section{Introduction}

The majority of offshore oil and gas facilities uses two or more redundant gas turbines to supply the electricity on board. The primary scope of platform operators is to ensure a continuous oil and gas production with minimum risk of failure for the plant during the entire lifetime of the reservoir. Compactness, low-weight and dynamic flexibility are pivotal design aspects to abate installation costs and maximize the economic revenue. Gas turbine-based power systems can comply with these requirements by virtue of their open-cycle configuration and the internal combustion process. However, energy conversion efficiencies higher than $40 \%$ are hardly achievable.

Aiming at alleviating the environmental footprint of oil and gas installations, industry and academia are currently focusing on a number of directions: i) electrification from onshore power plants [1, 2], ii) carbon capture and storage [3, 4], iii) integration of offshore wind power [5], and iv) implementation of waste heat recovery units [6-9]. Organic Rankine cycle (ORC) power systems have recently emerged as suitable technology [10, 11]. Favorable design features are high modularity, compactness and low weight. Nonetheless, the addition of an ORC module inherently increases the inertia of the system due to the additional heat transfer equipment. Furthermore, the plant reliability may diminish due to the added system complexity, thus forcing the platform operator to reschedule the maintenance activities.

In this context, the use of model predictive control (MPC) has the potential to enhance the dynamic flexibility of the plant and to ensure its safe operation. The MPC uses internal (linear or non-linear) models to determine the control action. Such implementation permits reduced settling times of the process variables compared to proportional-integral-derivative (PID) controllers. Model predictive control algorithms have been successfully applied in the refining and petrochemical industries, owing to the simplicity of the system and to the use of impulse or step response models [12]. The recent need for plant flexibility has led to an increasing interest in applying the MPC to onshore power plants. As an example, Sáez et al. [13] employed a MPC unit to control the start-up, normal operation, and shut-down of a combined cycle power plant. The proposed algorithm, tested in a model of a real system, improved the tracking capacities and decreased the fuel consumption by $3 \%$ [13]. Quoilin et al. [14] developed a dynamic model of an ORC unit based on first principles. The steady-state performance of the system was optimized for a number of operating conditions. Optimal process variables, e.g., the evaporating temperature, were selected as set-points of properly tuned feedback controllers. Similarly, Zhang et al. [15] developed a MPC unit to control an ORC module by deriving the reference trajectories with a steady-state optimizer. Peralez et al. [16] used a dynamic programming algorithm to maximize the power production of an ORC power system for dieselelectric railcars. The results show an increase of about $7 \%$ in the recovered energy compared to the supervisory control using static optimization. Luong [17] tested various control methods for waste heat recovery systems on heavy-duty trucks. 
Improved tracking capabilities were demonstrated using the MPC with respect to PID controllers. Hernandez et al. [18] investigated the use of a multivariable MPC to control efficiently the degree of superheating of a pilot ORC power system. The proposed controller could minimize the oscillations of the tracked variables compared to a PID controller.

A few studies demonstrated the applicability of MPC algorithms on offshore platforms. Imsland et al. [19] integrated a dynamic model of an offshore processing plant with a MPC simulation tool to control a four-stage oil separation process. Smoother responses for the measured outputs, i.e., the oil and water levels in the separator inlet, were demonstrated compared to standard controllers. Willersrud et al. [20] studied the application of MPCs for optimizing the oil generation of an offshore installation with particular focus on the production manifold. They surveyed that the total oil export could increment by around $70 \mathrm{Sm}^{3} \cdot \mathrm{d}^{-1}$, corresponding to a yearly increased revenue of $16 \mathrm{M} \$$.

To the authors' best knowledge, a control system using linear MPC integrated with a steady-state performance optimizer for offshore gas turbines and ORC turbogenerators has not been proposed in the literature yet. The paper aims at evaluating if: i) the control unit can maximize the thermal efficiency of the plant preserving its reliability, and ii) it can deliver faster dynamic responses compared to the controllers currently installed on offshore gas turbines. To address these research questions, the authors programmed in Simulink language the dynamic model of the ORC power system, as well as extended the original gas turbine model provided by the manufacturer. The controller is designed identifying the linear models of the process and tuning the controller parameters. A steady-state optimization unit tracks on-the-fly the maximum energy conversion efficiency of the plant. Moreover, the proposed control system monitors crucial process variables, i.e., the highest temperature of the working fluid in the ORC unit and the stack temperature at the outlet of the primary heat exchanger. This feature enables switching the operational strategy of the bottoming cycle unit if harmful operating conditions are met. Furthermore, the MPC controls the power station by respecting practical limits on the process and control variables.

First, the paper introduces (see Sec. 2) the case study of the present work. Subsequently, Sec. 3 describes the dynamic model of the power system comprising the gas turbine and the ORC turbogenerator. Here the implementation of the MPC is also outlined. The results are then reported and discussed in Sec. 4, and concluding remarks are given in Sec. 5.

\section{Case study}

This work considers an exemplary power system installed on the Draugen oil and gas offshore platform, located $150 \mathrm{~km}$ west of Kristiansund, in the Norwegian Sea. The reservoir was discovered in 1984, and started operation in 1993. The platform, operated by A/S Norske Shell, produces gas exported via the Åsgard gas pipeline to Kårstø (Norway) and oil, stored in tanks at the bottom of the sea and exported via a shuttle tanker. The nominal power demand is around $19 \mathrm{MW}$, and it can increase up to $25 \mathrm{MW}$ during oil export. Two turbines run at a time, each covering $50 \%$ of the load. A third engine is kept on stand-by, allowing for maintenance work and back-up in the case of failure. This strategy ensures the reserve power for peak loads and the safe operation of the engines. As a result, the yearly average energy conversion efficiency of the power system is around $25 \%$.

Figure 1 shows the layout of the modified power system with an additional ORC unit to recover the exhaust thermal power of one gas turbine. The layout omits the two remaining engines. The twin-spool gas turbine employs two coaxial 


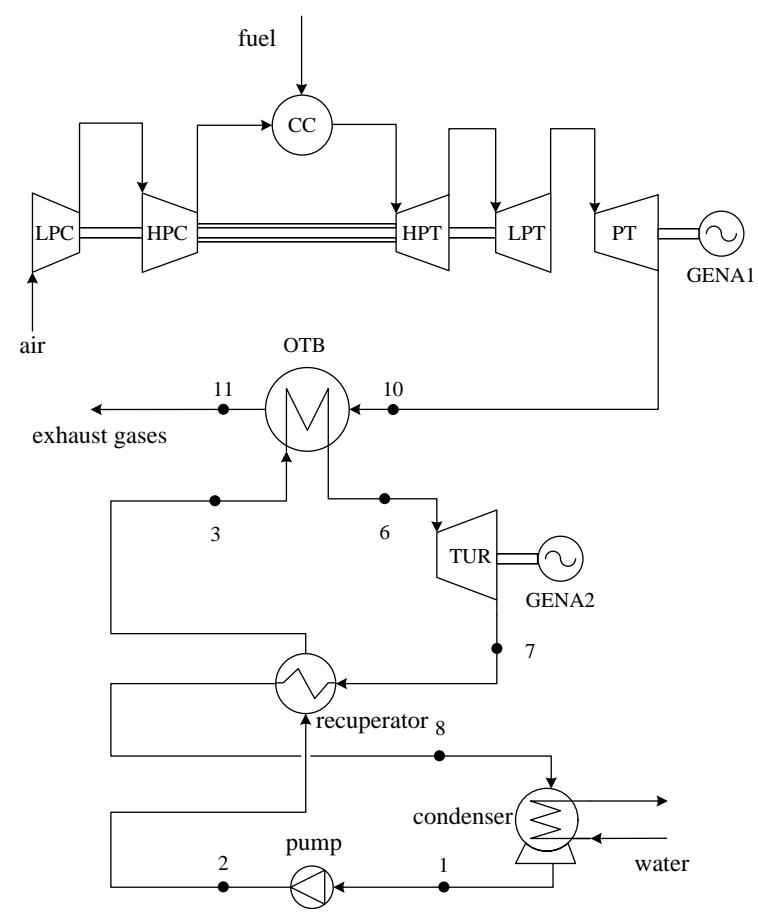

Fig. 1. Simplified layout of the power system on the Draugen offshore oil and gas platform; the exhaust gases of one engine feed the organic Rankine cycle module. The two remaining gas turbines are not shown.

shafts, coupling the low pressure compressor (LPC) with the low pressure turbine (LPT) and the high pressure compressor (HPC) with the high pressure turbine (HPT). The power turbine (PT) transfers mechanical power through a dedicated shaft to the electric generator (GEN). Natural gas is the fuel utilized in the combustion chamber (CC).

The ORC unit comprehends the single-pressure non-reheat once-through boiler (OTB), the turbine (TUR), the sea-water cooled shell-and-tube condenser and the feed-water pump. The tubes of the OTB are equipped with fins to enhance the heat transfer area on the exhaust gas side. The working fluid is cyclopentane, a compound widely adopted for operating ORC systems in this range of temperature; see, e.g., Del Turco et al. [21] and Colonna et al. [22]. The reader may refer to Pierobon et al. [10] and Bhargava et al. [11] for the optimization of the working fluid for ORC power systems on offshore platforms. As the slope of the saturation curve of cyclopentane is positive (dry fluid), a shell-and-tube recuperator is added to decrease the energy contained in the superheated vapor exiting the ORC expander. Figure 2 shows the $T-s$ diagram of the ORC power unit considered in this study. Starting from point 3 , cyclopentane is preheated $(3 \rightarrow 4)$, vaporized $(4 \rightarrow 5)$ and superheated $(5 \rightarrow 6)$ in the once-through boiler. The fluid is then expanded in the turbine $(6 \rightarrow 7)$, and cooled down in the recuperator $(7 \rightarrow 8)$. In this manner, the inlet temperature of the OTB can be enhanced by recovering energy from the superheated vapor exiting the turbine. The working fluid is then condensed $(8 \rightarrow 9 \rightarrow 1)$ and compressed $(1 \rightarrow 2)$ to the highest pressure level through the cold side of the recuperator $(2 \rightarrow 3)$, thus closing the cycle. Note that Fig. 1 does not report node 9 as the saturated vapor condition is met inside the condenser. 


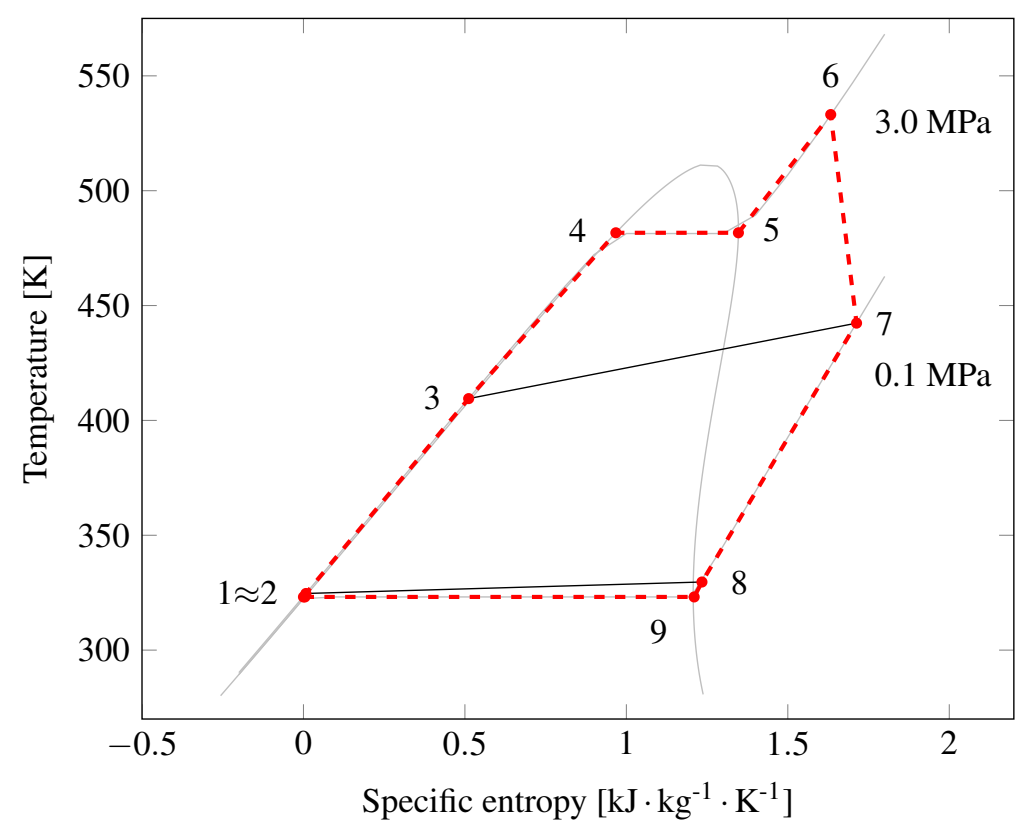

Fig. 2. Saturation curve of cyclopentane in a $T-s$ diagram, showing the thermodynamic cycle state points of the organic Rankine cycle system.

\section{Methods}

The present section contains the key attributes and the implementation of the control system. First, the dynamic model of the power station implemented on a Simulink block-diagram environment [23] is described. Subsequently, the arguments which led to the selection of the operational strategy for the bottoming unit are recounted. Finally, the design of the MPC is outlined.

\subsection{Model description}

Figure 3 shows the top-level diagram of the plant integrating the gas turbine and the ORC turbogenerator. The scheme includes also the control system consisting of the MPC unit and the steady-state optimizer. Sections 3.1.1 and 3.1.2 present the gas turbine and the ORC subsystems, respectively. The differential-algebraic equations describing the plant dynamics are solved using the implicit Euler method. As regarding the fluid models, the exhaust stream is treated as a mixture of ideal gases. The thermodynamic and transport properties of cyclopentane are calculated according to the open-source software developed by Bell et al. [24].

\subsubsection{The gas turbine}

The model of the topping unit is an extension of the original version developed by the engine manufacturer. It uses non-physical transfer functions to represent the dynamic behavior of the main gas turbine constituents. Figures 3 and 4 show the new control system and the original feedback loop designed by the manufacturer, respectively. The latter regulator serves to compare and quantify the performance of the new controller. The frequency signal (middle leftmost of Fig. 4) is first filtered and compared to the set-point value $(50 \mathrm{~Hz})$. The output then passes to the frequency controller (FRC) and to an integrator (valve), which sets the fuel valve position. The characteristic curve of the valve converts the signal into the actual 
heat input to the engine, whose injection is delayed by the block accounting for the mechanic inertia of the valve (fuel_sys). The heat rate is translated to the actual shaft power produced by the engine. This is modeled as a first-order transfer function (compressor), which accounts for the inertia of the rotating masses with the exception of the electric generators. The exhaust gas module provides the temperature and mass flow rate of the exhaust stream exiting the engine as a function of the ambient temperature and shaft power. The relations are based on interpolating functions covering a power range from $10 \%$ to full load.

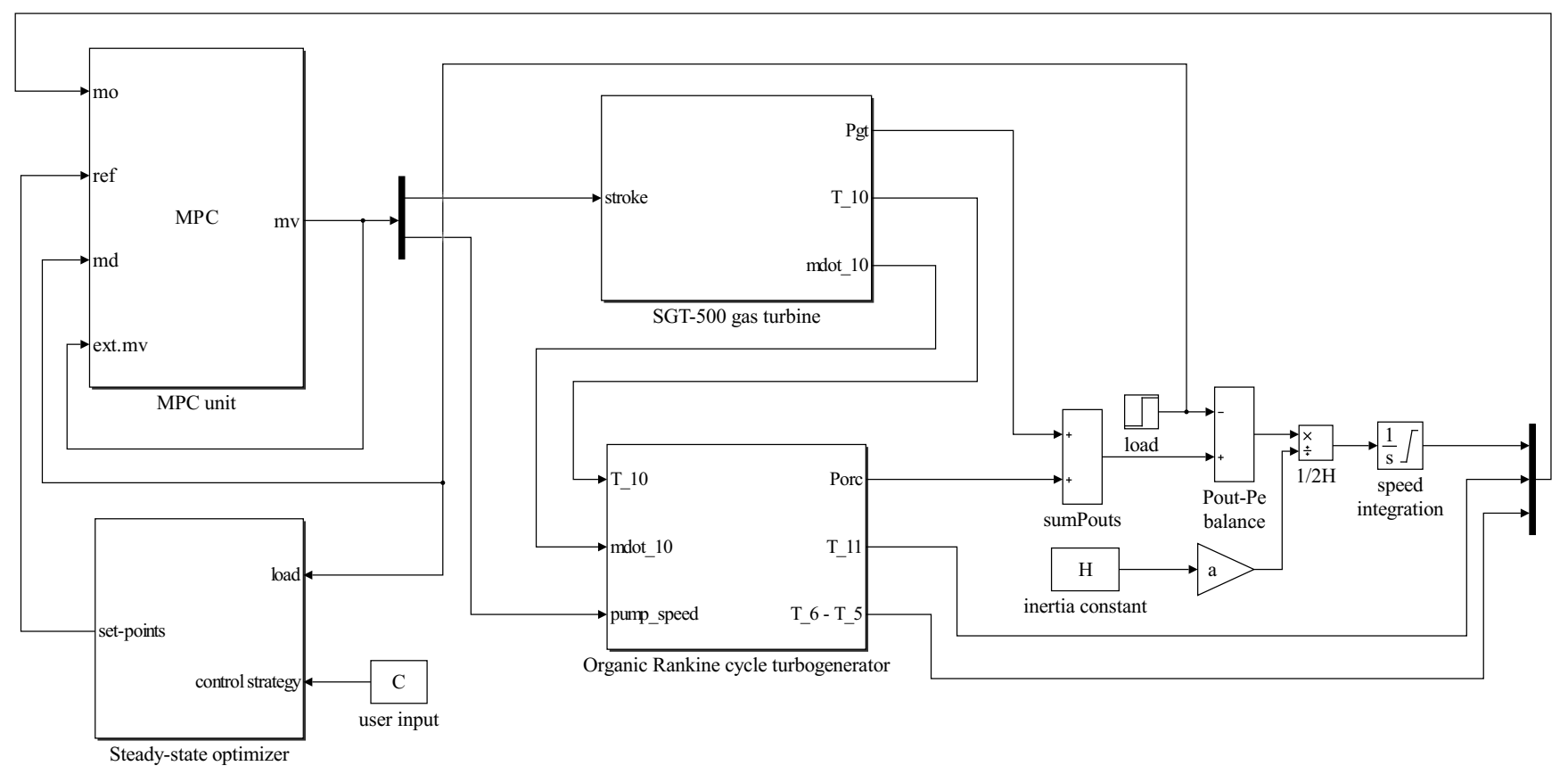

Fig. 3. Top-level scheme of the gas turbine connected to the ORC power module on the Simulink block-diagram environment.

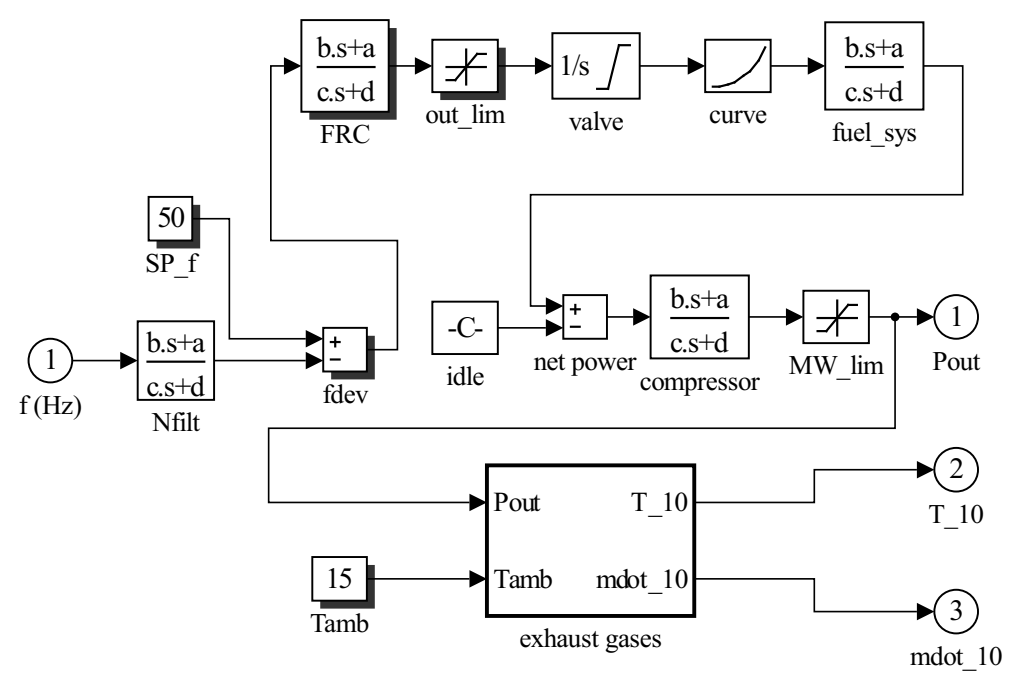

Fig. 4. Transfer function model of the gas turbine on the Simulink block-diagram environment as provided by the engine manufacturer. 


\subsubsection{The organic Rankine cycle turbogenerator}

The model of the ORC turbogenerator receives as inputs the temperature and the mass flow rate of the exhaust gases, as well as the signal containing the rotational speed of the pump, which in Fig. 3 is set by the MPC unit. The system of equations is programmed in the Matlab language. The model is embedded in the Simulink environment by exploiting the interpreted Matlab function block [23]. The transient performance of the ORC power system is considered to be driven by the inertia of the heat exchangers and rotating masses. Figure 5 shows the discretized model used to represent the once-through boiler and the recuperator. The model features a one-dimensional flow model for the hot side (top) and cold side (bottom), and a one-dimensional thermal model for the tube walls (middle). Counterflow configuration and uniform pressure distribution are assumed.

The tube metal wall is modeled by a one-dimensional dynamic heat balance equation, which for the $i$ th-cell reads

$$
C_{\mathrm{w}} \frac{d \bar{T}_{\mathrm{w}, \mathrm{i}}}{d t}=\dot{q}_{\mathrm{h}}-\dot{q}_{\mathrm{c}}
$$

where $C_{\mathrm{w}}$ is the heat capacity of the metal wall, and $\bar{T}_{\mathrm{w}, \mathrm{i}}$ is the wall temperature at the $i$ th-volume, calculated as the arithmetic average between the temperatures at the inner and the outer node. The variable $\dot{q}_{\mathrm{h}}$ is the heat provided by the hot stream, and $\dot{q}_{\mathrm{c}}$ is the heat transferred to the cold side. The flow model for the cold side contains one-dimensional dynamic mass and energy balance equations, which are expressed as

$$
V_{\mathrm{c}, \mathrm{i}} \frac{d\left(\bar{u}_{\mathrm{i}} \overline{\mathrm{c}}_{\mathrm{c}, \mathrm{i}}\right)}{d t}=\dot{m}_{\mathrm{i}} h_{\mathrm{i}}-\dot{m}_{\mathrm{i}+1} h_{\mathrm{i}+1}+\dot{q}_{\mathrm{c}},
$$

$$
V_{\mathrm{c}, \mathrm{i}} \frac{d \bar{\rho}_{\mathrm{c}, \mathrm{i}}}{d t}=\dot{m}_{\mathrm{i}}-\dot{m}_{\mathrm{i}+1}
$$

where $\dot{m}_{\mathrm{i}}$ and $h_{\mathrm{i}}$ represent the mass flow rate and the enthalpy at the $i$ th-node. The variables $\bar{u}_{\mathrm{c}, \mathrm{i}}$ and $\bar{\rho}_{\mathrm{c}, \mathrm{i}}$ are the internal specific energy and the density of the volume $V_{\mathrm{c}, \mathrm{i}}$, calculated as the arithmetic average between the values at the inner and the outer node. Given the relatively small variations with time of the thermodynamic properties on the gas side, steady-state mass and energy balances are considered. 


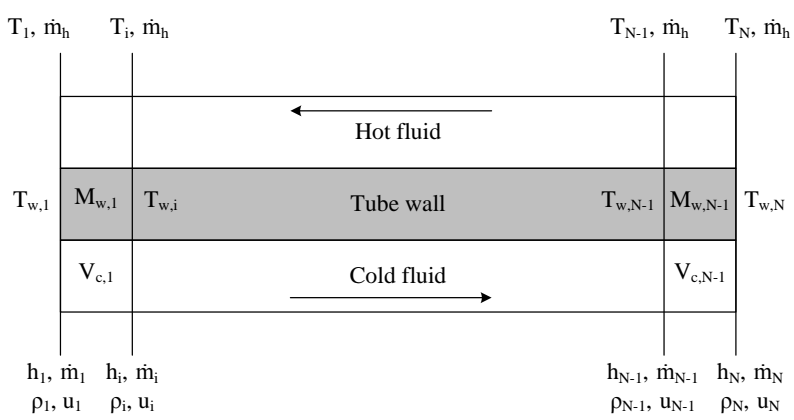

Fig. 5. Heat exchanger discretized model.

For the once-through boiler and the recuperator, the heat transfer coefficient between the hot and the outer pipe surface is much lower than the one between the inner pipe surface and the ORC working fluid flow. Therefore, the overall heat transfer is essentially dependent on the hot side only, and the working fluid temperature is always close to the inner surface temperature of the pipe. The heat transfer coefficient at the interface between the hot and the metal wall, in off-design conditions, is evaluated with the relation [25]

$$
U=U_{\mathrm{des}}\left(\frac{\dot{m}}{\dot{m}_{\mathrm{des}}}\right)^{\gamma}
$$

where $U$ is the heat transfer coefficient and the subscript "des" refers to the value at nominal operating conditions. The exponent $\gamma$, taken equal to 0.6 , is the exponent of the Reynolds number in the heat transfer correlation reported in VDI [26], originally derived for air in circular finned-tube heat exchangers. The thermal interaction between the wall and the cold stream is described by specifying a sufficiently high constant heat transfer coefficient, so that the fluid temperature is close to the wall temperature. The overall result is dominated by the hot side heat transfer. The pressure drop is lumped at the inlet of each heat exchanger, assuming a quadratic dependence with the volumetric flow rate.

In megawatt-size ORC units, the expander is typically a one or two-stage axial machine, leading to large pressure ratios across each stage. The flow is consequently supersonic at the outlet of the first stator. Therefore, the turbine is modeled as an equivalent de Laval nozzle, whose throat flow passage area is the sum of the throat areas of the nozzles constituting the first stator row. Isentropic expansion is assumed from the inlet section, where total conditions (total pressure $p_{\mathrm{T}, 6}$ and total temperature $T_{\mathrm{T}, 6}$ ) are assumed to be known by virtue of the thermodynamic state calculation, to the throat, where sonic 
conditions are attained, i.e., the flow speed equals the speed of sound $c$. The corresponding system of equations is

$$
\left\{\begin{array}{l}
s_{6}=s\left(p_{\mathrm{T}, 6}, T_{\mathrm{T}, 6}\right) \\
h_{\mathrm{S}, \mathrm{th}}=h_{\mathrm{T}, 6}\left(p_{\mathrm{T}, 6}, T_{\mathrm{T}, 6}\right)-\frac{1}{2} c\left(h_{\mathrm{S}, \mathrm{th}}, s_{6}\right)^{2} \\
\dot{m}=\rho_{\mathrm{S}, \mathrm{th}}\left(h_{\mathrm{S}, \mathrm{th}}, s_{6}\right) c\left(h_{\mathrm{S}, \mathrm{th}}, s_{6}\right) A_{\mathrm{th}},
\end{array}\right.
$$

where $s_{6}$ is the specific entropy at the turbine inlet, and the subscript " $\mathrm{S}$,th" indicates static conditions in the throat section. The continuity equation relates the mass flow rate through the nozzle $\dot{m}$ to the density $\rho_{\mathrm{S} \text {,th }}$ and the flow passage area $A_{\text {th }}$ in the throat section. For given design-point conditions, the total nozzle throat area is known. Equation 5 can be applied to relate the mass flow rate to the thermodynamic state at the turbine inlet. To predict the off-design performance of the turbine, the correlation relating the isentropic efficiency $\eta_{\text {is }}$ with the rotational speed $N$ and the isentropic enthalpy drop $\Delta h_{\text {is }}$ proposed by Schobeiri [27] is utilized.

$$
\eta_{\text {is }}=\eta_{\text {is,des }} \frac{N}{N_{\text {des }}} \sqrt{\frac{\Delta h_{\text {is,des }}}{\Delta h_{\text {is }}}}\left(2-\frac{N}{N_{\text {des }}} \sqrt{\frac{\Delta h_{\text {is,des }}}{\Delta h_{\text {is }}}}\right) .
$$

The off-design characteristic of the electric generator is modeled using the equation suggested by Haglind and Elmegaard [28]. The pump model is based on a head-volume flow curve derived by fitting the data of an existing centrifugal pump designed for similar volumetric flows and heads. The curve is given as a function of $\phi=\dot{m} / \rho \cdot \rho_{\mathrm{des}} / \dot{m}_{\mathrm{des}}$ and can be expressed as

$$
H=H_{\text {des }}\left(2.462-0.538 e^{\phi}\right)\left(\frac{N}{N_{\text {des }}}\right)^{2},
$$

where $H$ is the head. The exponential functional form is selected in order to result in a monotonic relation, thus increasing the model robustness compared to typically adopted polynomial expressions. The isentropic efficiency of the 
Table 1. Design-point variables used to parametrize the state-space model of the organic Rankine cycle unit.

\begin{tabular}{|c|c|}
\hline Component & Parameters \\
\hline \multicolumn{2}{|l|}{ Once-through boiler } \\
\hline Volume (cold side) & $8.5 \mathrm{~m}^{3}$ \\
\hline Weight (tube walls) & $39.2 \mathrm{t}$ \\
\hline UA-value $^{1}$ & $432.6 \mathrm{~kW} \cdot \mathrm{K}^{-1}$ \\
\hline Pressure drop (cold side $)^{1}$ & $103.1 \mathrm{kPa}$ \\
\hline Pressure drop (hot side) ${ }^{1}$ & $1.0 \mathrm{kPa}$ \\
\hline \multicolumn{2}{|l|}{ Recuperator } \\
\hline Volume (cold side) & $1.0 \mathrm{~m}^{3}$ \\
\hline Weight (tube walls) & $8.8 \mathrm{t}$ \\
\hline UA-value ${ }^{1}$ & $167.7 \mathrm{~kW} \cdot \mathrm{K}^{-1}$ \\
\hline Pressure drop (cold side) ${ }^{1}$ & $13.8 \mathrm{kPa}$ \\
\hline Pressure drop (hot side) ${ }^{1,2}$ & $41.5 \mathrm{kPa}$ \\
\hline \multicolumn{2}{|l|}{ Turbine } \\
\hline Throat section & $40.2 \mathrm{~cm}$ \\
\hline Isentropic enthalpy drop & $116.94 \mathrm{~kJ} \cdot \mathrm{kg}^{-1}$ \\
\hline \multicolumn{2}{|l|}{ Electric generator } \\
\hline Power output & $5098.2 \mathrm{~kW}$ \\
\hline Moment of inertia & $170 \mathrm{~kg} \cdot \mathrm{m}^{2}$ \\
\hline \multicolumn{2}{|l|}{ Pump } \\
\hline Enthalpy rise & $6.51 \mathrm{~kJ} \cdot \mathrm{kg}^{-1}$ \\
\hline Volumetric flow & $0.0537 \mathrm{~m}^{3} \cdot \mathrm{s}^{-1}$ \\
\hline
\end{tabular}

${ }^{1}$ The item refers to the value at design-point.

2 The item includes also the pressure drop on the hot side of the shell-and-tube condenser.

pump $\eta_{\mathrm{p}}$ is expressed as a function of the coefficient $F=\phi \cdot N_{\text {des }} / N$ using the methodology proposed by Veres [29].

$$
\eta_{\mathrm{p}}=\eta_{\mathrm{p}, \mathrm{des}}\left(0.86387+0.3096 F-0.14086 F^{2}-0.029265 F^{3}\right)
$$

Table 1 lists the parameters used to parametrize the state-space model of the ORC turbogenerator. The weight, volume and UA-values of the once-through boiler and the recuperator are set using the in-house simulation tool described in Pierobon et al. [30], which was extensively validated with public domain data. 


\subsubsection{Validation and verification}

As outlined in Sec. 3.1.1, the gas turbine model is an extension of the original version developed by the manufacturer. The model has been widely adopted by the engine producer to design and optimize the control units equipping their mediumsize industrial gas turbines. Furthermore, Iyengar et al. [31] performed an in-depth validation of the model using the data provided by the platform operator. This analysis estimated a relative error lower than $5 \%$ for the speeds of the rotating masses, i.e., the high and low pressure shafts and the electric generator, from $10 \%$ to full load.

As regarding the ORC unit, the dynamic model presented in Sec. 3.1.2 was verified using a similar implementation developed in Modelica language for the same type of power plant [30]. Note that the latter reference model of the ORC system was composed of software objects acquired from a library that was developed to model a $150 \mathrm{~kW}$ ORC system using toluene as the working fluid, and was successfully validated for transient operation against experimental data, as discussed in Casella et al. [32]. The comparison suggests that the relative error is lower than $2 \%$ for all the process variables related to the ORC module. The model of the bottoming cycle unit is, therefore, deemed reliable, considering the similarity of the application at hand with the one presented in the cited reference.

\subsection{Operational strategy}

The system under consideration operates off-grid. When integrating the ORC unit, four synchronous generators are connected in parallel and rotate at the same speed, as the electrical connections are very short. The gas turbine has the fastest load response. Its fuel valve controls the network frequency. The dynamic response of the ORC unit is far slower than that of the gas turbine. The mass flow rate through the ORC turbine and the generated power adapt slowly to load variations, owing to the large time constant of the bottoming cycle unit. This means that the contribution of the pump speed to the limitation of the frequency drop is marginal. Other relevant process variables can thus be monitored. As an example, Casella et al. [32] describe an ORC unit where the turbopump speed set-point, which determines the mass flow rate of the pump, controls the turbine inlet temperature, by means of a PID regulator. The reader may refer to Quoilin et al. [33] for a description of other control strategies suitable for ORC power systems. Recent investigations [14, 15] suggest the presence, at any given temperature and mass flow rate of the hot source, of an operating condition maximizing the power output of the ORC module.

Considering one gas turbine connected to the ORC unit, the thermal efficiency of the system can be defined as

$$
\eta_{\mathrm{th}}=\frac{\dot{P}_{\mathrm{GENA} 1}+\dot{P}_{\mathrm{GENA} 2}-\dot{P}_{\mathrm{p}}}{\dot{m}_{\mathrm{ng}} \mathrm{LHV}}
$$

where $\dot{P}_{\mathrm{p}}$ is the pump power consumption. The variables $\dot{P}_{\mathrm{GENA} 1}$ and $\dot{P}_{\mathrm{GENA} 2}$ are the powers produced by the electric generators serving the gas turbine and the ORC unit. The quantities $\dot{m}_{\mathrm{ng}}$ and LHV are the mass flow rate and the lower heating 


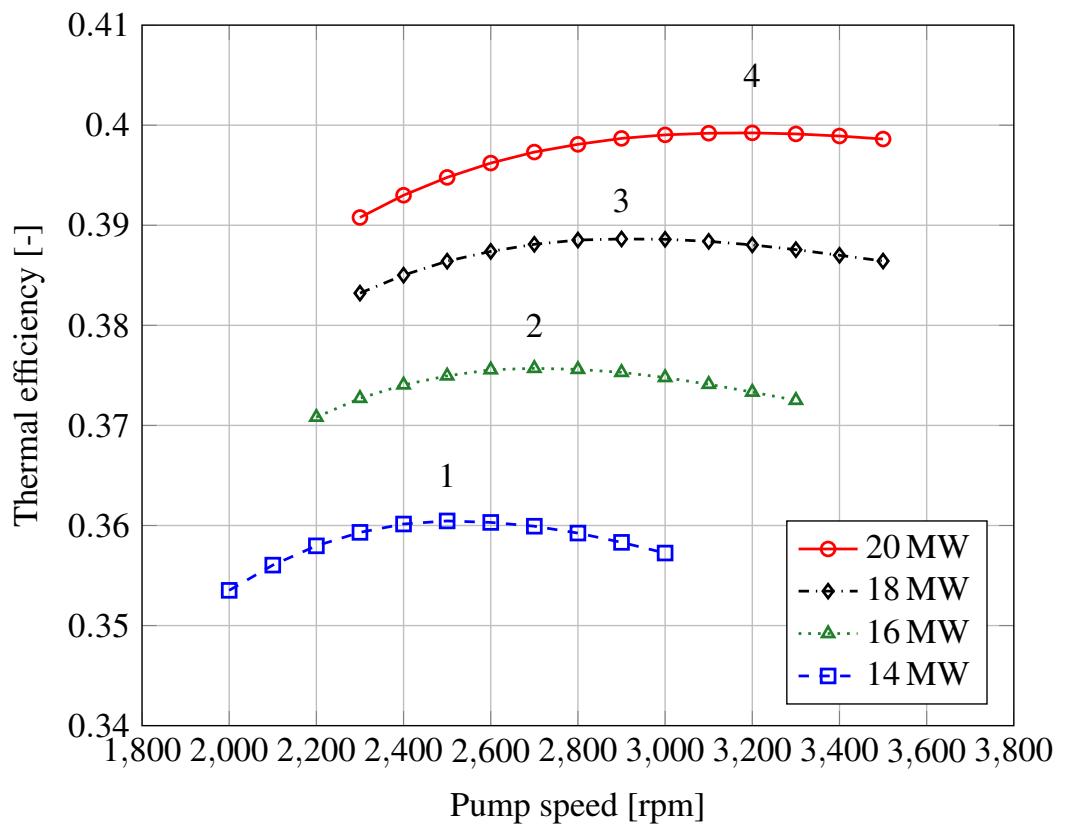

Fig. 6. Effect of the pump speed on the performance of the combined cycle unit and points of maximum thermal efficiency. The curves are given for four load set-points of the combined cycle plant.

value of the combustible. In steady-state conditions, the load demand is fixed and equal to the value of the numerator in Eq. 9 , assuming the pumping work to be negligible. Therefore, maximizing the energy conversion efficiency of the combined cycle plant entails the minimization of the fuel consumption, see Eq. 9. The degree of freedoms are the mass flow rate of the fuel and the pump speed. The fuel input is the variable used to achieve the load set-point. At the same time, the pump speed is controlled to maximize the thermal efficiency of the combined cycle unit. The optimal working point is reached when the power output of the bottoming cycle unit is maximized. This eventually leads to minimize the share of power supplied by the gas turbine since the sum of the powers provided by the two generators is constant and equal to the load set-point. This allows the plant operator to reduce the fuel consumption. Figure 6 shows the effect of the pump speed on the thermal efficiency of the combined cycle plant at different load set-points. These results are obtained by simulating the plant with the parameters listed in Tab. 1. The higher the power duty, the larger the thermal efficiency and the pump speed that maximizes the system performance. Note that the ORC turbogenerator operates in sliding pressure mode. The evaporating pressures are governed by Eq. 5, the pump curve and the heat balances in the heat transfer equipment.

Figure 7 shows the degree of superheating $T_{6}-T_{5}$ and the stack temperature $T_{11}$ as a function of the combined cycle load. The rotational speed of the pump is set, for each load, to the value providing the highest energy conversion efficiency. The trend of the optimal degree of superheating is relatively flat with an average of $\approx 35 \mathrm{~K}$, see Figure $7 \mathrm{a}$. This may lead the working fluid to enter the expander in vapor-liquid conditions for sharp load changes, due to the low degree of superheating. This event may damage the turbine blades owing to the formation of liquid droplets at the first turbine nozzle. To tackle the problem, the degree of superheating is the process variable used to track the efficiency peaks. This choice allows exploiting the capability of the MPC to handle hard constraints on the measured outputs.

Unlike conventional combined cycle power plants, the gas turbine is not equipped with variable inlet guide vanes. The 
engine load can only be controlled by adjusting the fuel valve. As a consequence, the temperature $T_{10}$ drops down for decreasing loads. Therefore, tracking the efficiency peaks at low power duties $(<40 \%)$ entails temperatures $T_{11}$ lower than $413 \mathrm{~K}$, see Figure $7 \mathrm{~b}$. Lower temperatures may increase the probability of acid formation in the terminal part of the once-through boiler, owing to the condensation of corrosive compounds. Note that the problem may occur at higher stack temperatures if high-sulfur fuels are used to fire the SGT-500 engines. It is thus decided to design the control system (refer to Sec. 3.3) with the possibility of keeping constant and equal to $413 \mathrm{~K}$ the temperature $T_{11}$ of the exhaust gases released to the environment. The thermal efficiency of the combined cycle unit is no longer at the optimum with such operational strategy. However, the plant operator can minimize the risk of acid formation.

\subsection{Control system design}

The left side of Fig. 3 illustrates the block-diagrams of the MPC system and of the steady-state optimizer. The main task of the first unit is to hold the measured outputs (MOs) of the process, i.e., the network frequency and the degree of superheating, at their reference values (REFs) by acting on the manipulated variables (MVs), in this case, the valve position and the pump speed. The measured disturbance (MD) is the power demand measured at the terminals of the electric generators. The design of the MPC unit requires a model relating the measured disturbances and the manipulated variables to each measured output. Linear plant models derived with step response tests are used [34], given the relatively low complexity of the power system treated here. The software described in Chan et al. [35] was used to identify the process models. The MPC implementation is based on the algorithm embedded in the widely adopted toolbox described in Bemporad et al. [36]. Appendix A provides the transfer functions used as internal models for the model predictive control. No correspondence between the pump speed and the frequency, as well as between the valve position and the other measured outputs was assumed. As explained in Sec. 3.2, the control problem can be split into two separate sub-problems by virtue of the difference in the time constants of the topping and bottoming engines. The primary task, i.e., to satisfy the platform load and maintain

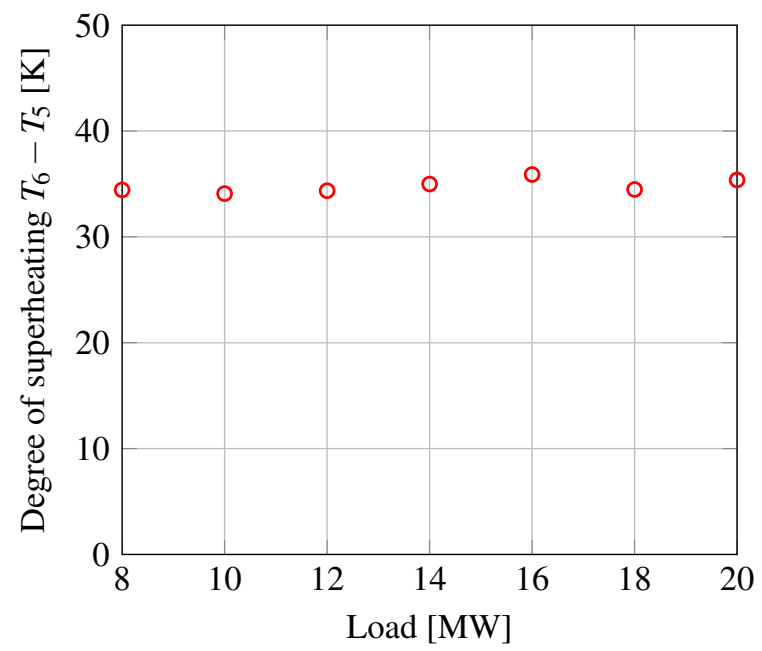

(a) Degree of superheating

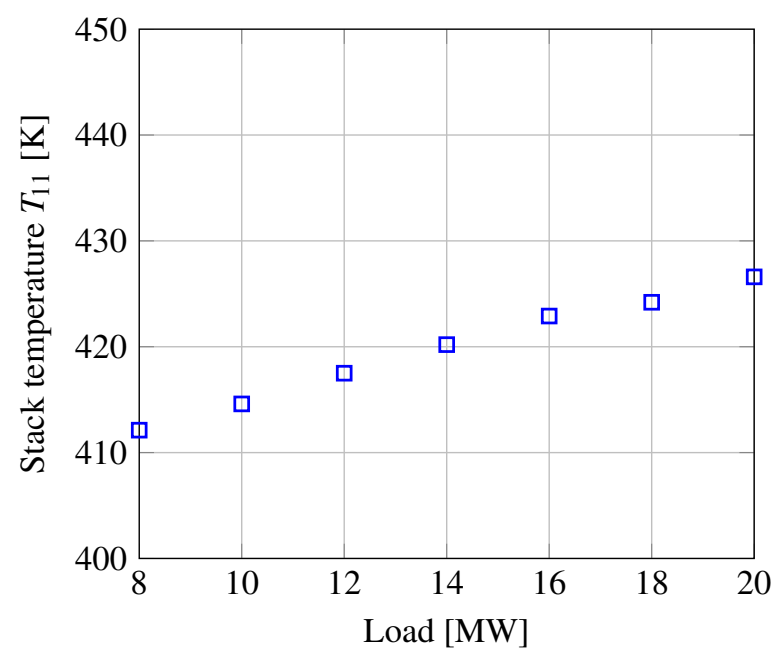

(b) Stack temperature

Fig. 7. Degree of superheating $T_{6}-T_{5}$ and stack temperature $T_{11}$ as a function of the combined cycle load. The rotational speed of the pump is set to the optimal value, see Figure 6. 
the frequency set-point, can be accomplished by adjusting the fuel valve. The pump speed can not provide a significant contribution due to the inertia of the ORC turbogenerator. On the other hand, the latter variable can deliver properly selected set-points for process variables related to the Rankine engine. These considerations led to setting null-transfer functions for the valve position and the measured outputs related to the ORC module, as well as for the pump speed and the grid frequency. This practical implementation prevents the MPC unit from performing the regulation of the frequency using the pump speed, and vice versa, to track a given degree of superheating, by changing the valve position.

The model predictive control action at time $k$ is obtained by solving the following optimization problem

$$
\begin{array}{r}
\min \{J(\Delta \boldsymbol{u}, \boldsymbol{\varepsilon})\}=\sum_{z=0}^{p-1}[\boldsymbol{y}(k+z+1 \mid k)-\boldsymbol{r}(k+z+1)]^{T} \\
\boldsymbol{Q}[\boldsymbol{y}(k+z+1 \mid k)-\boldsymbol{r}(k+z+1)] \\
+\Delta \boldsymbol{u}(k+z \mid k)^{T} \boldsymbol{R}_{\Delta u} \Delta \boldsymbol{u}(k+z \mid k)+\rho_{\mathrm{e}} \varepsilon^{2},
\end{array}
$$

subject to the constraints

$$
\left\{\begin{array}{l}
\boldsymbol{u}_{\min }-\varepsilon \boldsymbol{V}_{\min }^{u} \leq \boldsymbol{u} \leq \boldsymbol{u}_{\max }+\varepsilon \boldsymbol{V}_{\max }^{u} \\
\Delta \boldsymbol{u}_{\min }-\varepsilon \boldsymbol{V}_{\min }^{\Delta u} \leq \Delta \boldsymbol{u} \leq \Delta \boldsymbol{u}_{\max }+\varepsilon \boldsymbol{V}_{\max }^{\Delta u} \\
\boldsymbol{y}_{\min }-\varepsilon \boldsymbol{V}_{\min }^{y} \leq \boldsymbol{y} \leq \boldsymbol{y}_{\max }+\varepsilon \boldsymbol{V}_{\max }^{y} \\
\Delta \boldsymbol{u}(k+z \mid k)=0 \\
\varepsilon \geq 0
\end{array}\right.
$$

where $\boldsymbol{y}, \boldsymbol{u}$ and $\boldsymbol{r}$ are the vectors of the measured outputs, the manipulated variables and the set-points, respectively. The integer $p$ is the prediction horizon. On the right side of Eq. 10, the first term represents the primary objective of the optimization, i.e., to minimize the difference between the plant outputs and the reference points. The diagonal positive semi-definite matrix $\boldsymbol{Q}$ contains the weight factors on each set-point deviation. The second contribution discourages abrupt adjustments of the manipulated variables which may occur when tracking the reference targets. The slack variable $\varepsilon$ supported by the weight factor $\rho_{\mathrm{e}}$ allows adjusting the impact of the constraint violations on the objective function $J$. In analogy to $\boldsymbol{Q}$, the diagonal and positive semi-definite matrix $\boldsymbol{R}_{\Delta u}$ enables the user to weight the relative contribution of the second term in Eq. 10. The subscripts "min" and "max" refer to the lower and upper bounds imposed on the manipulated variables and the measured outputs. The positive vectors $\boldsymbol{V}_{\min }$ and $\boldsymbol{V}_{\max }$ represent the concern for relaxing the corresponding constraint. The adopted toolbox converts Eqs. 10 and 11 to a quadratic programming problem solved using the algorithm proposed by Schmid and 
Biegler [37]. The reader is referred to Bemporad et al. [36] for an in-depth description of the mathematical formulation and solution of the optimization problem.

The reference trajectories of the ORC unit are computed by the steady-state optimizer, shown at the bottom leftmost of Fig. 3. This component, activated by variations of the load set-point, uses a steady-state version of the plant model described in Sec. 3.1 to determine the plant configuration with the highest thermal efficiency. The equations are the same as those used in the dynamic model with all the derivatives set to zero. Given a load variation, the optimizer performs this task by solving an optimization problem, using the rotational speed of the pump as the variable. In the routine, the fuel flow is automatically varied to satisfy the power demand. The algorithm is based on the simplex method for function optimization described by Nelder and Mead [38]. This procedure allows determining the optimal set-point for the degree of superheating in the new steady-state condition. A delay of $2 \mathrm{~s}$ is added to the signal transmitting the set-point of the degree of superheating in order to account for the computational time required to solve the optimization problem. The optimizer can change the control to constant stack temperature automatically, if the stack temperature $T_{11}$ exceeds the limit for sulphuric acid formation ( $413 \mathrm{~K}$ is here selected to preserve the fuel flexibility of the gas turbine). In this case, the thermal efficiency of the combined cycle unit and the degree of superheating are not optimal, as the priority becomes the safe operation of the power system. Note that the platform operator has the possibility of manually selecting the desired control strategy independently from the optimizer.

Table 2 lists the variables assumed to initialize the MPC unit. Note that the control system and the ORC model act

Table 2. Parameters, weight factors and bounds assumed to initialize the model predictive control unit.

\begin{tabular}{|c|c|c|}
\hline Parameter & & Value \\
\hline Sampling time $[\mathrm{ms}]$ & & 100 \\
\hline Control horizon [s] & & 20 \\
\hline Prediction horizon $[\mathrm{s}]$ & & 100 \\
\hline \multicolumn{3}{|l|}{ Weight factor } \\
\hline Valve stroke rate [-] & & 10 \\
\hline Pump speed rate [-] & & $1 \cdot 10^{3}$ \\
\hline Frequency [-] & & 1 \\
\hline Stack temperature [-] & & 100 \\
\hline Degree of superheating [-] & & 100 \\
\hline Bound & Minimum & Maximum \\
\hline Valve stroke [-] & 0.145 & 0.66 \\
\hline Valve stroke rate $\left[\mathrm{s}^{-1}\right]$ & -0.33 & 0.33 \\
\hline Pump speed [rpm] & 1,500 & 3,500 \\
\hline Pump speed rate $\left[\mathrm{rpm} \cdot \mathrm{s}^{-1}\right]$ & -10 & 10 \\
\hline Frequency tolerance [\%] & -5 & 5 \\
\hline Stack temperature $[\mathrm{K}]$ & 413 & - \\
\hline Degree of superheating [K] & 5 & - \\
\hline
\end{tabular}


on a discrete domain with a sampling time of $100 \mathrm{~ms}$. Accordingly, the blocks representing the power plant model and the continuous transfer functions were converted to discrete time. The prediction horizons, the weight factors $r_{\Delta u i, i}$ and the coefficients of the diagonal matrices $\boldsymbol{R}_{\Delta u}$ and $\boldsymbol{Q}$ in Eq. 10 were tuned to achieve a compromise between well-damped responses of the measured outputs and rapid tracking of the reference trajectories. The steady-state optimizer automatically selects the operational strategy of the ORC unit, e.g., the constant stack temperature, by assigning the weight factor reported in Tab. 2 to the temperature $T_{11}$, and imposing a null-weight factor on the degree of superheating $T_{6}-T_{5}$. As for the bounds on the manipulated variables and their rate variations $\left(\boldsymbol{u}_{\min }, \Delta \boldsymbol{u}_{\min }\right.$ and $\left.\boldsymbol{u}_{\max }, \Delta \boldsymbol{u}_{\max }\right)$ and on the measured outputs $\left(\boldsymbol{y}_{\min }\right.$ and $\left.\boldsymbol{y}_{\max }\right)$, these are treated as hard constraints $\left(\boldsymbol{V}_{\min }\right.$ and $\boldsymbol{V}_{\max }$ equal to 1$)$. Their numerical values were selected based on proprietary information provided by the gas turbine manufacturer and on data available in the open literature.

\section{Results and discussion}

This section presents and discusses the simulation results for the proposed control system. The first part is dedicated to quantify the advantages compared to the feedback control loop designed by the gas turbine manufacturer, and the latter part shows the results of the control system applied to the power plant integrating the gas turbine and the ORC module.

\subsection{Comparison with the feedback control loop}

The MPC regulator is first applied to control one gas turbine without the waste heat recovery unit. This allows comparing the performance of the regulator provided by the engine manufacturer with the MPC. The models used to design the controller are those given in Eqs. 12 - 13; see Appendix A. The control action governing the fuel valve solves Eq. 10, subject to Eq. 11, with the boundary conditions stated in Tab. 2 . The steady-state optimizer is not active, since the ORC power system is not considered at this stage. Figure 8a shows the responses of the gas turbine operated by the model predictive control unit and by the feedback controller of the engine manufacturer. The change of load set-point is $4 \mathrm{MW}$. With the original control system, the maximum frequency undershooting reaches a value of $3.0 \%$, while the MPC gives $1.7 \%$. Note also that the rise time, i.e., the time required for the frequency to return back to $99.0 \%$ of the steady-state value, is around $10 \mathrm{~s}$ lower with the MPC. Figure 9a shows the frequency undershooting in percent as a function of the step in the load set-point. The proposed control system can decrease the frequency drop in the range of $20-40 \%$. These advantages are particularly evident for the largest load changes. Figure $9 \mathrm{~b}$ shows the rise time for each variation of the load set-point. For the largest steps $(3 \mathrm{MW}$ and $4 \mathrm{MW}$ ), the regulator reacts in $1.7 \mathrm{~s}$ and $2.5 \mathrm{~s}$, respectively. The feedback controller of the manufacturer takes around 6-times more. Similar rise times are observed with step variations between $1 \mathrm{MW}$ and $2 \mathrm{MW}$. An average reduction of $20 \%$ is observed when varying the initial load set-point of the engine from 20 to $100 \%$ of its nominal power.

The enhanced performance is due to the feed-forward action, which allows the MPC unit to counteract immediately the measured disturbance without any large feedback gains. This gives enhanced stability and robustness. However, the effectiveness depends on having a high-fidelity model tuned to the operating conditions. Techniques for adaptation and learning [35] are thus necessary to optimize the control action over time. Figure 8b illustrates the variation of the valve opening produced by the two control systems over time. At $t_{0}=100 \mathrm{~s}$, the load set-point varies from 8 to $12 \mathrm{MW}$. However, 


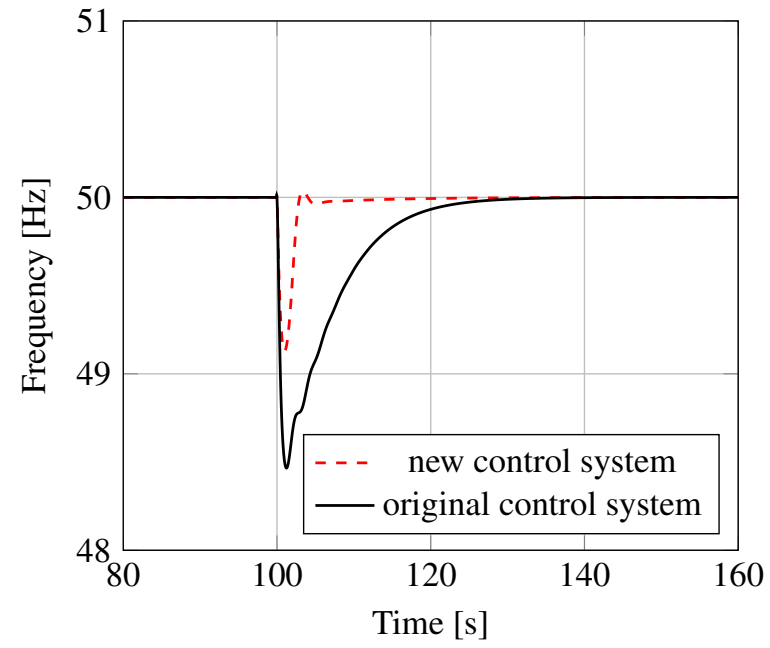

(a) Frequency

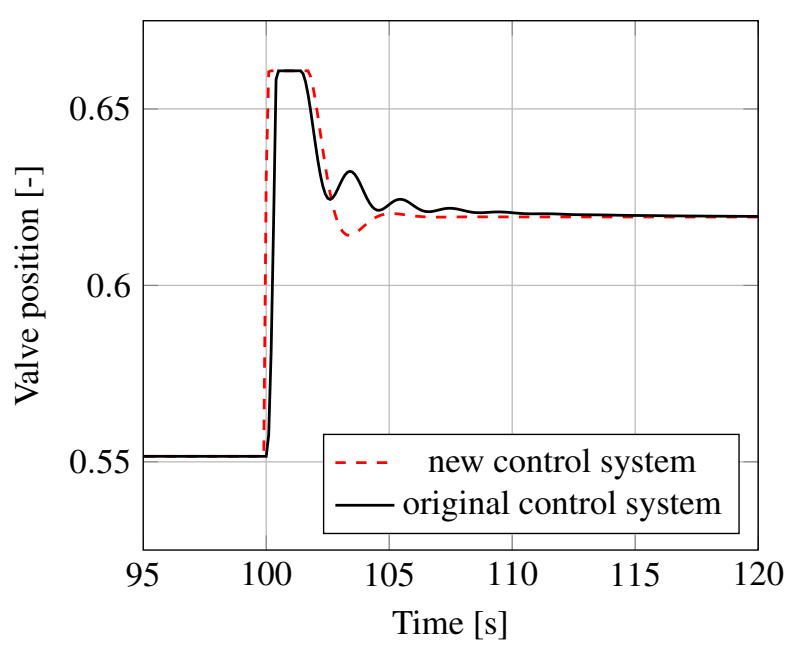

(b) Valve position

Fig. 8. Dynamics of the frequency and valve position as delivered by the controller of the gas turbine manufacturer and by the model predictive control system for a load step of $4 \mathrm{MW}$.

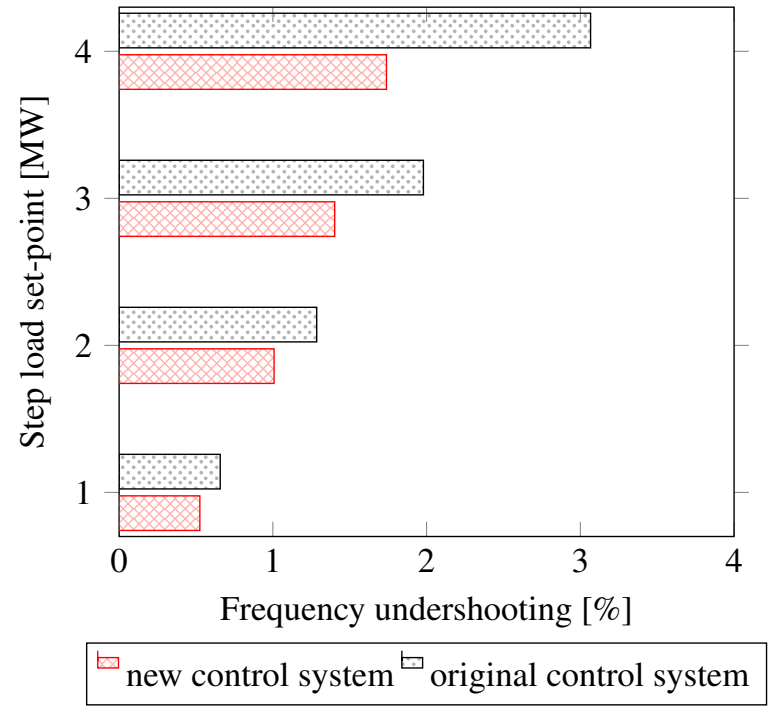

(a) Frequency undershooting

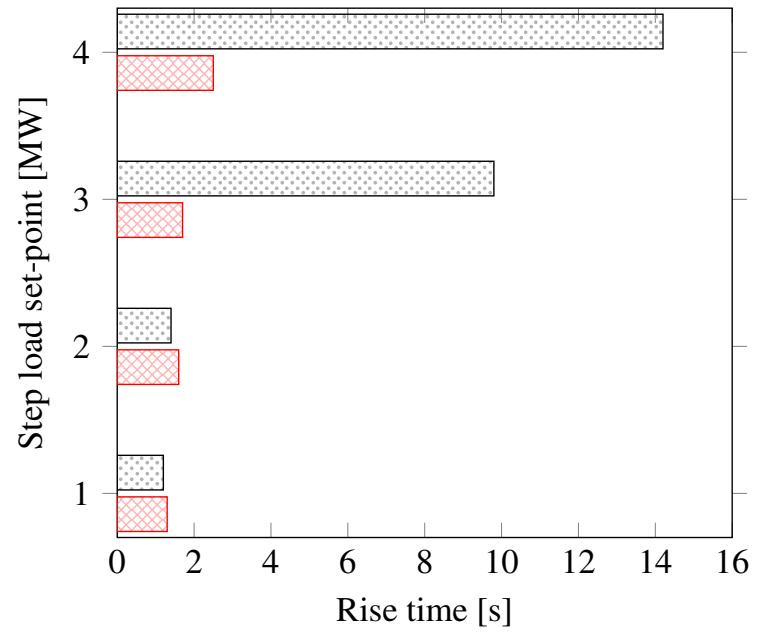

new control system ${ }^{\square}$ original control system

(b) Rise time

Fig. 9. Comparison of the dynamic metrics given by the controller of the gas turbine manufacturer and by the model predictive control system.

no control action is observable from the feedback controller until time $t_{1}=t_{0}+0.1$. Here the sensors detect the frequency deviation, and transfer the information to the control loop. Conversely, the MPC system increases the fuel flow at time $t_{0}=$ $100 \mathrm{~s}$, using the internal models relating the measured disturbance and the valve position to the frequency of the grid.

\subsection{Control of the combined cycle plant}

Here the dynamics of one gas turbine connected to the ORC turbogenerator is presented. The MPC system uses the internal models expressed by Eqs. 14 - 17; see Appendix A. The remaining settings for the controller are given in Tab. 2. The steady-state optimizer is now active. Its task is to identify, for a given load set-point, the degree of superheating delivering 
the highest performance of the plant, as well as to verify the feasibility of the working point. Figure 6 shows the running points of the plant, i.e., 1 and 2, when tracking the maximum plant efficiency for a power set-point increment from 14 to $16 \mathrm{MW}$. Given the practicability of the new working point, the steady-state optimizer transmits the optimal set-point of the degree of superheating to the MPC unit. Null-weight factor is imposed in the matrix $\boldsymbol{Q}$ (see Eq. 10) for the deviation of the remaining reference trajectory, i.e., the stack temperature. The dotted lines in Fig. 10 show the dynamic characteristics of the power system during the load modulation.

\subsubsection{Control stability}

The effect of fouling in the once-through boiler is simulated in order to assess the stability of the control action. Figure 10 provides the response of the plant, after a reduction of the overall heat transfer coefficient in the once-through boiler of $15 \%$. This event models a progressive fouling of the piping system. As such, it represents an unmeasured change in the dynamic response of the system. The internal models are unvaried. This numerically perturbs the optimization problem expressed by Eq. 10. Note that, at this stage, the part-load model of the steady-state optimizer was adapted to ensure the identification of the optimal plant efficiency. The frequency of the grid and the corresponding valve position (see Figs. 10a and 10b) are maintained, showing that the unmeasured disturbance neither induces control instabilities nor affects the transient characteristics of the plant. This statement applies also when tracking the degree of superheating (refer to Fig. 10c), by regulating the rotational speed of the pump (see Fig. 10d). As regarding the shaft powers delivered by the gas turbine and the ORC expander, Figs. 10e and 10f indicate that the fouling induces a reduction of around $5 \%$ in the share of power supplied by the bottoming cycle unit. These experiments demonstrate the stability of the control action, even when introducing a large unmeasured disturbance which perturbs the plant dynamics. This tendency is also observable by running the simulation at different initial load set-points. The tests show that the controller operates efficiently over the entire validity range of the developed models, i.e., from 20 to $100 \%$ of the nominal combined cycle power.

\subsubsection{Operations at low power activities}

Operating at the maximum thermal efficiency entails colder stack temperatures for decreasing power outputs. Acid formation is not a problem in this system for loads larger than $40 \%$. However, lower capacities lead to working conditions potentially harmful for the integrity of the outlet tubes of the once-through boiler, as the stack temperature approaches $413 \mathrm{~K}$. At power set-points lower than $10 \mathrm{MW}$, the steady-state optimizer detects the infeasibility of the optimal cycle configuration. Thus, it switches the operational strategy to constant stack temperature. This is carried out by resetting the weight factors on the measured outputs, as in Tab. 2 for the stack temperature, and to zero for the optimal degree of superheating.

Figure 11 compares the stack temperature as a function of time by operating at the maximum efficiency and at constant temperature $T_{11}$. The plant supplies $10 \mathrm{MW}$, and its load set-point decreases by $2 \mathrm{MW}$ at time $t_{0}=100 \mathrm{~s}$. The solid line indicates that at around $40 \%$ load, the optimal working condition of the plant is met at a temperature $T_{11}$ lower than $413 \mathrm{~K}$, which is harmful for the equipment. The plot also shows that operating at fixed stack temperatures entails a temperature undershooting lower than $10 \mathrm{~K}$. As regarding the plant activities near the design-point power capacity $(\approx 22 \mathrm{MW})$, the 


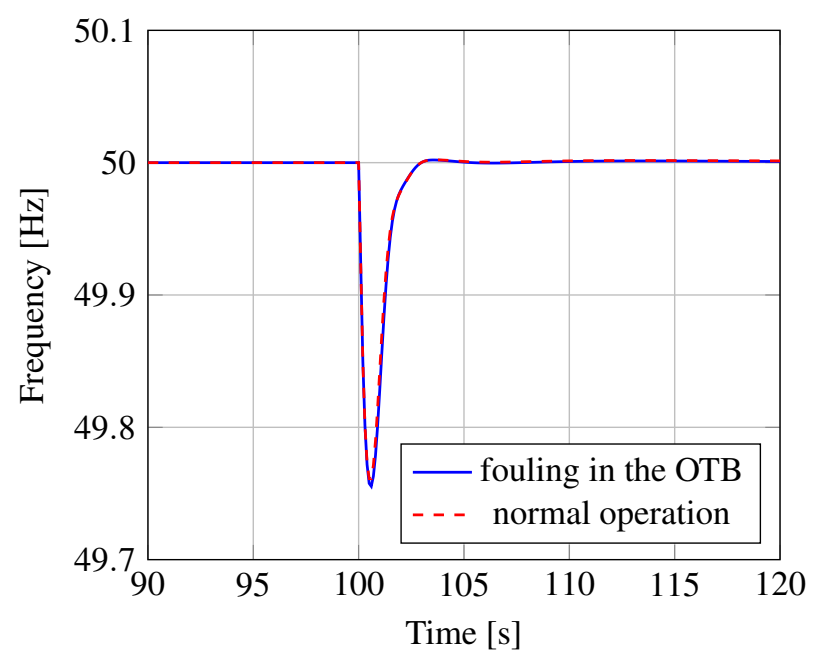

(a) Frequency

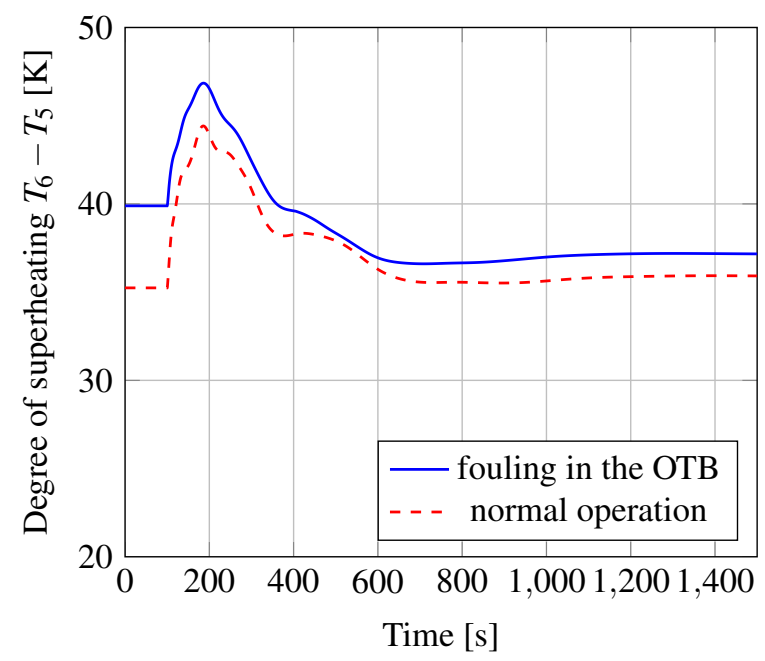

(c) Degree of superheating

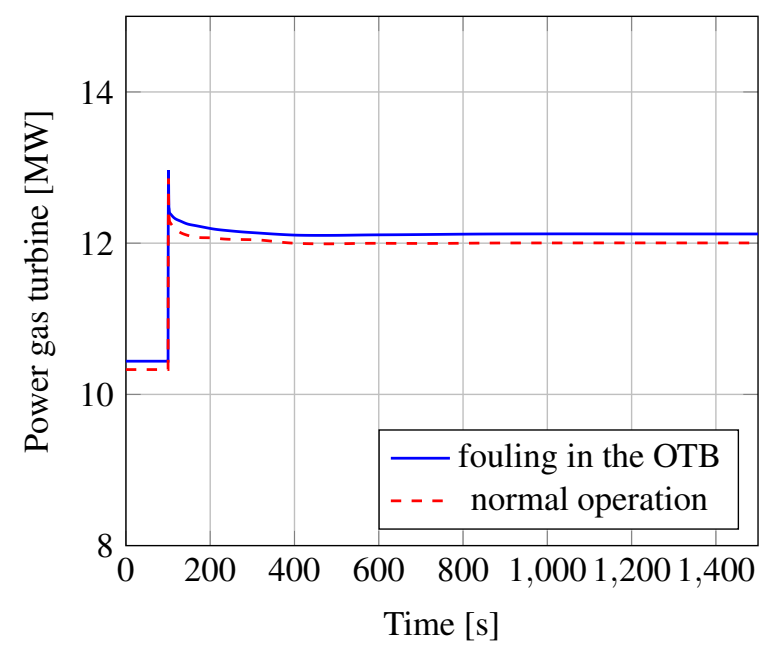

(e) Shaft power of the gas turbine

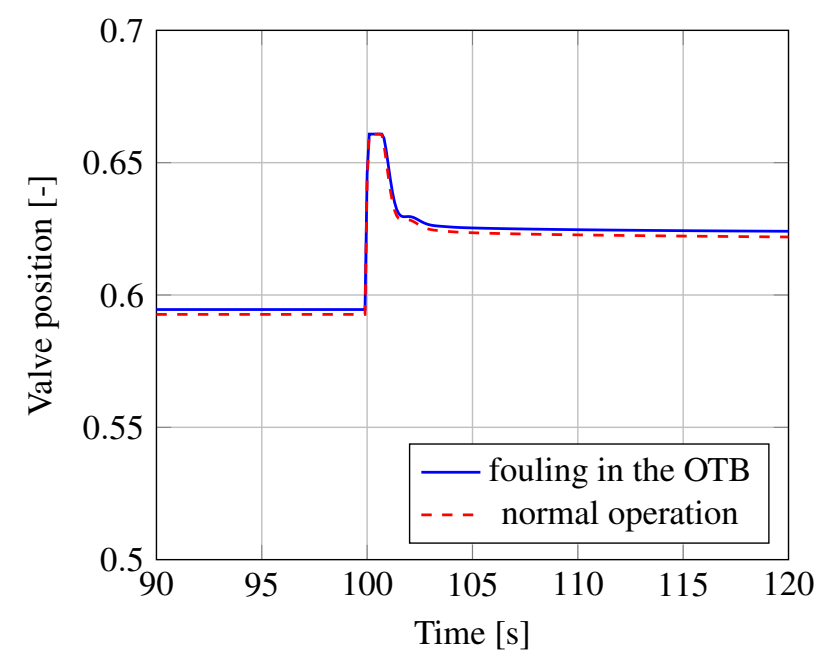

(b) Valve position

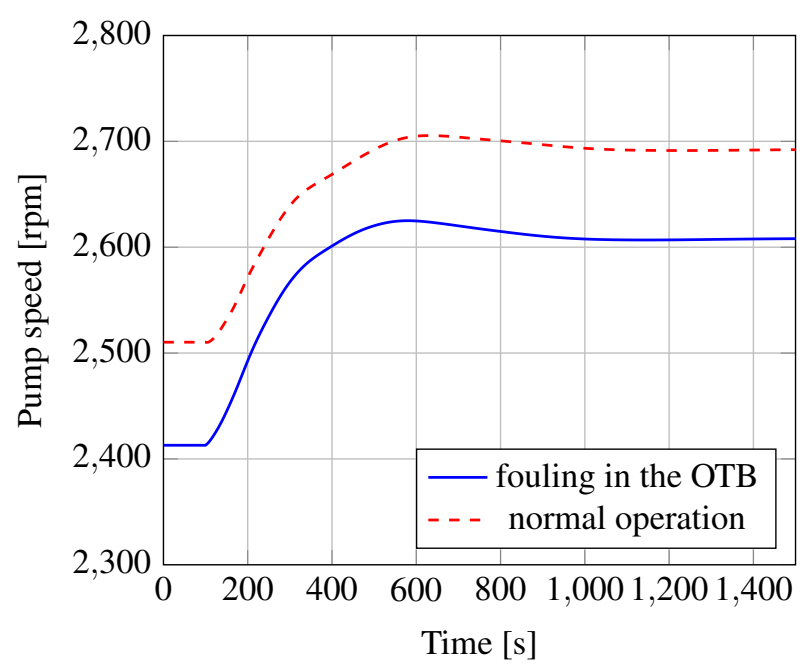

(d) Rotational speed of the pump

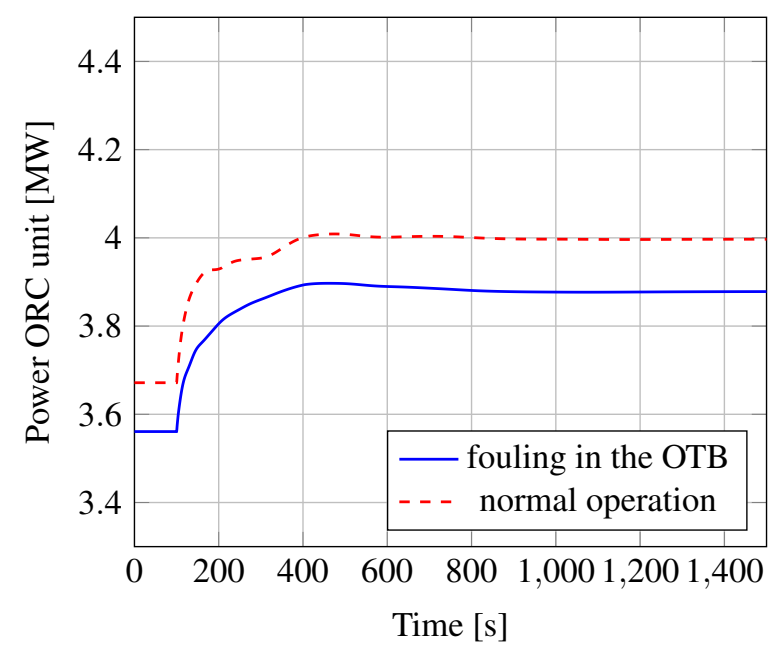

(f) Shaft power of the ORC unit

Fig. 10. Dynamic response of the combined cycle unit in normal operation and after a $15 \%$ deterioration of the overall heat transfer coefficient induced by fouling in the tubes of the once-through boiler. 


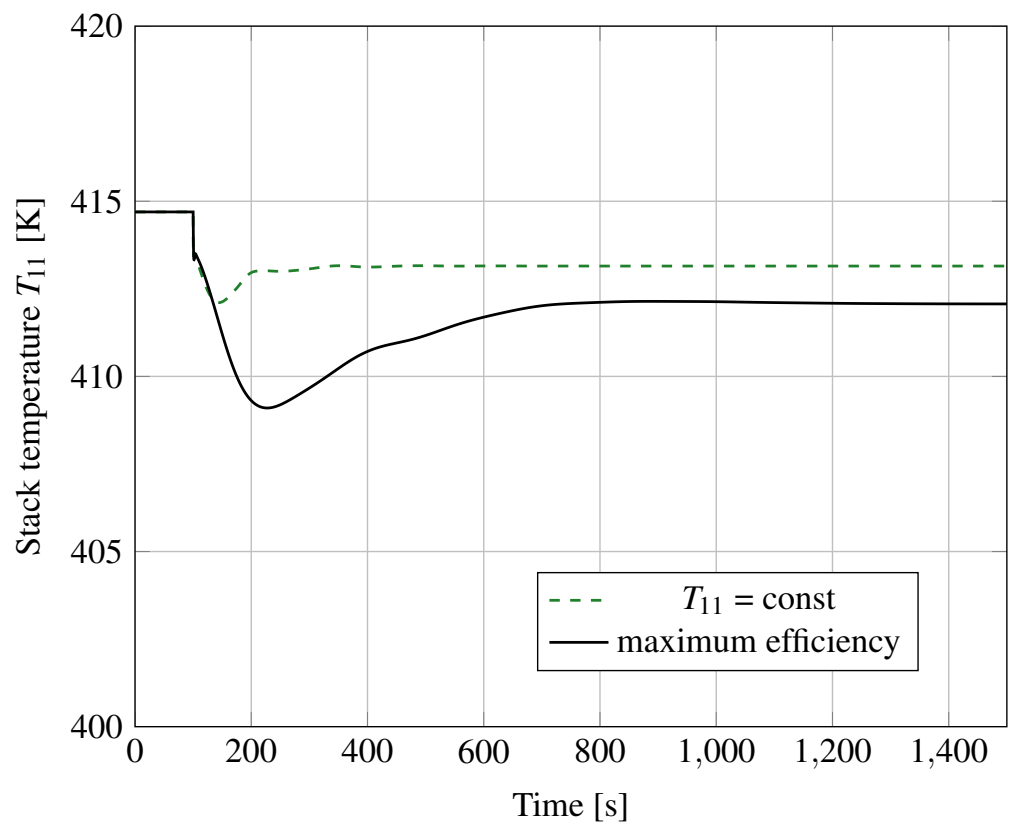

Fig. 11. Dynamic response of the combined cycle unit for two different control modes, i.e., operation at peak efficiency and constant stack temperature.

system can operate at the maximum efficiency with limited risk of decomposition for the working fluid. Recent surveys demonstrated the thermal stability of cyclopentane up to $543 \mathrm{~K}[39,40]$. This temperature is only encountered at the end metal wall of the once-through boiler by running the plant at power duties larger than $120 \%$ of the nominal load.

\subsubsection{Fuel savings and emission reduction}

The implementation of the steady-state optimizer enables running the power system at the highest energy conversion efficiency. Other alternative strategies are: i) fixed design-point turbine inlet temperature (543 K), and ii) constant designpoint stack temperature $(438 \mathrm{~K})$. The former allows one to monitor the highest temperature of the ORC turbogenerator and, thus, the decomposition of the working fluid. The latter strategy enables having a safe margin for the condensation of the corrosive acids in the OTB. Note that the set-points for the two temperatures are retrieved from the design-point cycle configuration.

These control strategies are compared considering the data of the load demand provided by the platform owner for the year 2012. Figure 12 reports the duration curve of the electric load on the Draugen platform. The values on the ordinate are normalized with respect to the yearly average load, i.e., $19 \mathrm{MW}$. It is assumed that the combined cycle unit runs in parallel with a second engine. The gas turbine and the ORC unit provide a constant power output equal to14 MW. Conversely, the load of the second gas turbine is adjusted to cover the remaining power demand. The plant model is run in steadystate conditions in order to quantify the yearly fuel saving and emission reduction. The $\mathrm{CO}_{2}$ savings are computed with the available fuel consumption assuming a conversion factor of $2.45 \mathrm{~kg}\left(\mathrm{CO}_{2}\right) \cdot \mathrm{kg}(\text { fuel })^{-1}$. The ambient temperature and pressure are assumed constant and equal to $298 \mathrm{~K}$ and $101325 \mathrm{~Pa}$.

The part-load simulations are performed for each control strategy. The results suggest that the use of the steady-state 
optimizer can boost the average yearly thermal efficiency of the system up to $0.5 \%$-points, compared to the case with fixed turbine inlet temperature and with constant stack temperature. The results also indicate a possible reduction of the yearly fuel consumption in the range of $2-3 \%$, and a corresponding decrease in carbon dioxide production of around $1.1 \mathrm{t} \cdot \mathrm{d}^{-1}$. The results are significant considering that they relate to a change in control strategy. No equipment modification is needed, and the regulator is easily implementable using standard software modifications.

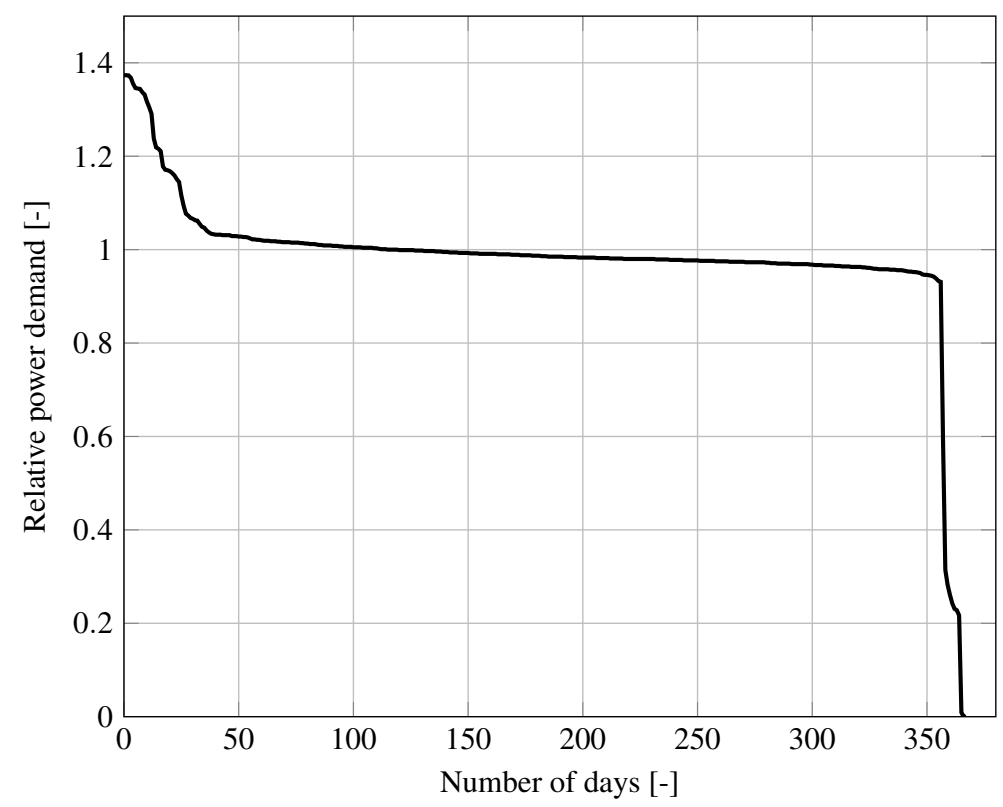

Fig. 12. Duration curve of the electric load in 2012 on the Draugen oil and gas platform.

\subsection{Limitations and future improvements}

As reported in Sec. 4.1, the proposed control system can reduce the frequency drop in the range of $20-40 \%$. Similar improvements can be achieved considering the control of the combined cycle plant. On the other hand, the controller of the manufacturer was designed for the operation of the gas turbine alone. A tuning of the controller would be necessary to properly quantify the benefits of the linear MPC with respect to the feedback controller, if the waste heat recovery unit is in operation. Nevertheless, the results clearly show the significant improvements in terms of plant dynamic flexibility when using the proposed control system, compared to PID regulators.

The use of feed-forward control for the valve position and the pump speed should be investigated, being more simple and cost-effective than the MPC. Future work will aim to compare the frequency dynamics using feed-forward control and the two regulators investigated in this work, so as to assess thoroughly the potential of the MPC. On the other hand, regulating the pump speed using the MPC or feed-forward control can arguably improve the dynamics of the bottoming unit compared to a simple PID. The gas turbine governs the transient response of the combined cycle plant. Therefore, a model-based controller applied to the pump speed can marginally affect the dynamics of the ORC unit. On the other hand, it enables the safe operation of the power system by handling constraints on control and process variables. As an example, tracking the 
optimal degree of superheating with the constraints given in Tab. 2 allows one to prevent the working fluid from entering the expander in vapor-liquid conditions and damaging the turbine blades; see Sec. 3.2.

Considering the results reported in Sec. 4.2, a real-time update of the MPC models is not mandatory. Nevertheless, the implementation of adaptation and learning techniques is recommendable to maximize the performance of the MPC unit [35]. In this case study, methods for adaptation and learning become a powerful instrument not only to preserve the stability of the control action, but also to correctly identify the actual point of highest energy conversion efficiency. The peak may eventually shift during real plant activities, e.g., the cause being the aging of the components; see Sec. 4.2.1. A real-time update of the internal models is presently beyond the capabilities of the present work. This feature can be implemented, e.g., by employing methods based on exergetic and thermoeconomic indicators [41,42]. These techniques are capable of identifying the components responsible for the departure of the simulation results from the recorded data, so that the models can be tuned accordingly.

The control system proposed in this paper couples a linear MPC to a steady-state optimizer. However, the same controller could be realized by adopting non-linear model predictive algorithms [34]. Such an implementation enables tracking the maximum efficiency of the plant, e.g., by setting an unreachable set-point based on the Carnot's theorem. Nonetheless, difficulties in solving the non-convex optimization problem translate into a significant increase of the computational time. This issue limits the practicability of this approach to slow processes at the present [34]. In this context, advances in modeling techniques, with particular focus on faster calculations of fluid physical properties, are necessary to exploit fully the potentials of the non-linear MPC.

\section{Conclusions}

This paper presents an advanced control system for offshore power stations consisting of gas turbines and organic Rankine turbogenerators. The controller uses a linear model predictive regulator and a steady-state performance optimizer to ensure the quality of the power supply and to operate at the highest energy conversion efficiency. An additional feature of the control system is the capability of switching on-the-fly the operational strategy of the Rankine engine, when potentially harmful working points are encountered. The simulation results demonstrate the ability of the proposed control unit to reduce the maximum frequency drop up to $40 \%$. Dynamic tests also prove the stability of the control action, even in the presence of large disturbances. Moreover, fuel savings and spared $\mathrm{CO}_{2}$ emissions in the range of 2 - $3 \%$ are foreseen by introducing the steady-state performance optimizer. The proposed controller is also applicable for improving the tracking capabilities of control systems for novel emerging applications, such as waste heat recovery in automotive engines, solar thermal plants, etc.

\section{Acknowledgements}

The funding from the Norwegian Research Council through Petromaks with project number 203404/E30 is acknowledged. The authors also acknowledge the kind support from Siemens Industrial Turbomachinery AB, Finspång, Sweden for providing the necessary technical documentation. 


\section{References}

[1] de Alegría, I. M., Martín, J. L., Kortabarria, I., Andreu, J., and Ereño, P. I., 2009. "Transmission alternatives for offshore electrical power". Renewable and Sustainable Energy Reviews, 13(5), pp. 1027-1038.

[2] Jones, P., and Stendius, L., 2006. "The challenges of offshore power system construction. Troll A, electrical power delivered successfully to an oil and gas platform in the north sea”. In European Wind Energy Conference, pp. 75-78.

[3] Hetland, J., Kvamsdal, H. M., Haugen, G., Major, F., Kårstad, V., and Tjellander, G., 2009. "Integrating a full carbon capture scheme onto a 450MWe NGCC electric power generation hub for offshore operations: Presenting the Sevan GTW concept”. Applied Energy, 86(11), pp. 2298-2307.

[4] Torp, T. A., and Gale, J., 2004. "Demonstrating storage of $\mathrm{CO}_{2}$ in geological reservoirs: The Sleipner and SACS projects”. Energy, 29(9), pp. 1361-1369.

[5] He, W., Jacobsen, G., Anderson, T., Olsen, F., Hanson, T. D., Korpås, M., Toftevaag, T., Eek, J., Uhlen, K., and Johansson, E., 2010. "The potential of integrating wind power with offshore oil and gas platforms". Wind Engineering, 34(2), pp. 125-137.

[6] Nord, L. O., and Bolland, O., 2012. "Steam bottoming cycles offshore - Challenges and possibilities". Journal of Power Technologies, 92(3), pp. 201-207.

[7] Walnum, H. T., Nekså, P., Nord, L. O., and Andresen, T., 2013. "Modelling and simulation of $\mathrm{CO}_{2}$ (carbon dioxide) bottoming cycles for offshore oil and gas installations at design and off-design conditions". Energy, 59(0), pp. 513 520.

[8] Bolland, O., Førde, M., and Hånde, B., 1996. “Air bottoming cycle: use of gas turbine waste heat for power generation”. ASME J Gas Turb Pwr, 118(2), pp. 359-368.

[9] Pierobon, L., Benato, A., Scolari, E., Haglind, F., and Stoppato, A., 2014. "Waste heat recovery technologies for offshore platforms". Applied Energy, 136(0), pp. 228 - 241.

[10] Pierobon, L., Nguyen, T.-V., Larsen, U., Haglind, F., and Elmegaard, B., 2013. "Multi-objective optimization of organic Rankine cycles for waste heat recovery: Application in an offshore platform”. Energy, 58, pp. 538-549.

[11] Bhargava, R., Bianchi, M., Branchini, L., De Pascale, A., Melino, F., Peretto, A., and Valentini, E., 2014. "Thermoeconomic evaluation of ORC system in off-shore applications". In ASME Turbo Expo 2014. Paper No. GT2014-25170.

[12] Qin, S. J., and Badgwell, T. A., 1996. "An overview of industrial model predictive control technology". In $5^{\text {th }}$ International Conference on Chemical Process control, pp. 232-256.

[13] Sáez, D., Zúñiga, R., and Cipriano, A., 2008. "Adaptive hybrid predictive control for a combined cycle power plant optimization". International Journal of Adaptive Control and Signal Processing, 22(2), pp. 198-220.

[14] Quoilin, S., Aumann, R., Grill, A., Schuster, A., Lemort, V., and Spliethoff, H., 2011. "Dynamic modeling and optimal control strategy of waste heat recovery organic Rankine cycles". Applied Energy, 88(6), pp. 2183-2190.

[15] Zhang, J., Zhou, Y., Wang, R., Xu, J., and Fang, F., 2014. "Modeling and constrained multivariable predictive control for ORC (organic Rankine cycle) based waste heat energy conversion systems". Energy, 66, pp. 128-138.

[16] Peralez, J., Tona, P., Nadri, M., Dufour, P., and Sciarretta, A., 2015. "Optimal control for an organic Rankine cycle on 
board a diesel-electric railcar". Journal of Process Control, 33(0), pp. 1 - 13.

[17] Luong, D., 2013. "Modeling, estimation, and control of waste heat recovery systems". PhD thesis, University of California, Los Angeles. See also URL https://escholarship.org.

[18] Hernandez Naranjo, J. A., Desideri, A., Ionescu, C., Quoilin, S., Lemort, V., and De Keyser, R., 2014. "Increasing the efficiency of organic Rankine cycle technology by means of multivariable predictive control". In $19^{\text {th }}$ World Congress of the International Federation of Automatic Control, pp. 2195-2200.

[19] Imsland, L., Kittilsen, P., and Schei, T. S., 2010. "Model-based optimizing control and estimation using Modelica models". Modeling, Identification and Control, 31(3), pp. 107-121.

[20] Willersrud, A., Imsland, L., Hauger, S. O., and Kittilsen, P., 2013. "Short-term production optimization of offshore oil and gas production using nonlinear model predictive control”. Journal of Process Control, 23(2), pp. 215-223.

[21] Del Turco, P., Asti, A., Del Greco, A., Bacci, A., Landi, G., and Seghi, G., 2011. "The ORegen waste heat recovery cycle: Reducing the $\mathrm{CO}_{2}$ footprint by means of overall cycle efficiency improvement". In ASME Turbo Expo 2011. Paper No. GT2011-45051.

[22] Colonna, P., Casati, E., Trapp, C., Mathijssen, T., Larjola, J., Turunen-Saaresti, T., and Uusitalo, A., 2015. “Organic Rankine cycle power systems: From the concept to current technology, applications, and an outlook to the future". ASME J Gas Turb Pwr, 137(10), pp. 1-19.

[23] The MathWorks, Inc., 2014. Getting Started with SIMULINK. The MathWorks, Inc., Natick, Massachusetts, March.

[24] Bell, I. H., Wronski, J., Quoilin, S., and Lemort, V., 2014. "Pure and pseudo-pure fluid thermophysical property evaluation and the open-source thermophysical property library CoolProp". Industrial \& Engineering Chemistry Research, 53(6), pp. 2498-2508.

[25] Incropera, F. P., DeWitt, D. P., Bergman, T. L., and Lavine, A. S., 2007. Fundamentals of Heat and Mass Transfer, 6 ed. John Wiley \& Sons, Inc., Jefferson City, Missouri. ISBN: 9780471457282.

[26] Verein Deutscher Ingenieure , 1953. VDI-Wärmeatlas: Berechnungsblätter für den Wärmeübergang. Springer-Verlag, Berlin, Germany. ISBN: 9783540412014.

[27] Schobeiri, M., 2005. Turbomachinery flow physics and dynamic performance. Springer Berlin, Berlin, Germany. ISBN: 9783540223689.

[28] Haglind, F., and Elmegaard, B., 2009. "Methodologies for predicting the part-load performance of aero-derivative gas turbines". Energy, 34(10), pp. $1484-1492$.

[29] Veres, J. P., 1994. Centrifugal and axial pump design and off-design performance prediction. Tech. rep., NASA, Sunnyvale, United States of America. Technical Memorandum 106745.

[30] Pierobon, L., Casati, E., Casella, F., Haglind, F., and Colonna, P., 2014. "Design methodology for flexible energy conversion systems accounting for dynamic performance”. Energy, 68, pp. 667-679.

[31] Iyengar, K., Rambabu, K., and Ydstie, E. B., 2013. "Dynamic modeling and control of gas turbines in combined cycle power plants". In AIChE Annual Meeting.

[32] Casella, F., Mathijssen, T., Colonna, P., and van Buijtenen, J., 2012. "Dynamic modeling of ORC power systems". 
ASME J Gas Turb Pwr, 135(4), pp. 1-12.

[33] Quoilin, S., Broek, M. V. D., Declaye, S., Dewallef, P., and Lemort, V., 2013. "Techno-economic survey of organic Rankine cycle (ORC) systems”. Renewable and Sustainable Energy Reviews, 22, pp. 168-186.

[34] Camacho, E. F., and Alba, C. B., 2013. Model predictive control. Springer, London, Great Britain. ISBN: 9780857293985 .

[35] Chan, K., Dozal-Mejorada, E., Cheng, X., Kephart, R., and Ydstie, B., 2014. "Predictive control with adaptive model maintenance: Application to power plants". Computers \& Chemical Engineering, 70, pp. 91-103.

[36] Bemporad, A., Morari, M., and Ricker, N. L., 2014. Model Predictive Control Toolbox For Use with MATLAB. The MathWorks, Inc., Natick, Massachusetts, March.

[37] Schmid, C., and Biegler, L. T., 1994. "Quadratic programming methods for reduced hessian SQP". Computers \& chemical engineering, 18(9), pp. 817-832.

[38] Nelder, J. A., and Mead, R., 1965. “A simplex method for function minimization”. The Computer Journal, 7(4), pp. 308-313.

[39] Ginosar, D. M., Petkovic, L. M., and Guillen, D. P., 2011. "Thermal stability of cyclopentane as an organic Rankine cycle working fluid". Energy \& Fuels, 25(9), pp. 4138-4144.

[40] Pasetti, M., Invernizzi, C. M., and Iora, P., 2014. "Thermal stability of working fluids for organic Rankine cycles: An improved survey method and experimental results for cyclopentane, isopentane and n-butane". Applied Thermal Engineering, 73(1), pp. $764-774$.

[41] Lazzaretto, A., Toffolo, A., Reini, M., Taccani, R., Zaleta-Aguilar, A., Rangel-Hernandez, V., and Verda, V., 2006. "Four approaches compared on the TADEUS (thermoeconomic approach to the diagnosis of energy utility systems) test case". Energy, 31(10-11), pp. 1586-1613.

[42] Lazzaretto, A., and Toffolo, A., 2006. "A critical review of the thermoeconomic diagnosis methodologies for the location of causes of malfunctions in energy systems". Journal of Energy Resources Technology, 128(4), pp. 335-342.

\section{Appendix A - Internal models}

This appendix contains the transfer function models implemented in the MPC unit to control the power system installed on the Draugen platform. The models are presented first for the gas turbine alone, and subsequently for the plant consisting of one gas turbine and the ORC turbogenerator.

\section{The gas turbine without the ORC unit}

Two step tests are necessary to relate the measured disturbance (platform load) and the manipulated variable (valve position) to the measured output (network frequency). The first test imposes a step variation of the platform load (4 MW is assumed) maintaining the valve opening constant. The second step test is performed by applying a step modulation of the stroke $(7 \%)$ at a fixed platform load. This procedure provides data to determine two internal models for the MPC unit. In 
the Laplace-domain, the two transfer functions $W(s)$ read

$$
W_{\text {load }}(s)=\frac{-0.6966}{s}
$$

$$
W_{f}(s)=\frac{66.11 s+55.09}{s^{3}+3.73 s^{2}+1.33 s}
$$

where $s$ is the complex argument of the Laplace transform. Note that the normalized root mean square value is higher than $99.4 \%$ for both transfer functions.

\section{The gas turbine and the ORC unit}

The power system comprises one gas turbine connected to the ORC turbogenerator. The degrees of freedom for the control logic are the valve position and the rotational speed of the pump. Given the step variations of the load demand $(2 \mathrm{MW})$ and of the valve position $(2.5 \%)$, the transfer functions relating the platform load and the first manipulated variable (valve stroke) to the frequency are

$$
W_{\text {load }}(s)=\frac{-0.5350}{s}
$$

$$
W_{f}(s)=\frac{48.23 s+30.61}{s^{3}+2.64 s^{2}+0.80 s}
$$

In both cases, the normalized root mean square value is larger than $99.0 \%$. The Laplace expressions connecting the pump speed to the degree of superheating $T_{6}-T_{5}$ and to the stack temperature $T_{11}$ were evaluated assuming a step variation of $300 \mathrm{rpm}$ with the other inputs fixed. The transfer functions for the stack temperature exiting the once-through boiler and 
for the degree of superheating read

$$
W_{T_{11}}(s)=10^{-3} \frac{-12.15 s-43.3}{s^{2}+28.9 s+0.84},
$$

$$
W_{T_{6}-T_{5}}(s)=10^{-3} \frac{3.75 s^{2}-1.35 s-6.97 \cdot 10^{-2}}{s^{3}+0.2 s^{2}+0.046 s+8.96 \cdot 10^{-4}}
$$

The normalized root mean square value for Eqs. 16 - 17 is higher than $92.9 \%$. 